\title{
Resistance in Maize Inbred Lines to Fusarium verticillioides and Fumonisin Accumulation in South Africa
}

I. M. Small, Department of Plant Pathology, University of Stellenbosch, Private Bag X1, Matieland 7602, South Africa; B. C. Flett, Grain Crops Institute, Agricultural Research Council, Private Bag X1251, Potchefstroom 2520, South Africa; and W. F. O. Marasas and A. McLeod, Department of Plant Pathology, M. A. Stander, Central Analytical Facility, and A. Viljoen, Department of Plant Pathology, University of Stellenbosch, South Africa

\begin{abstract}
Small, I. M., Flett, B. C., Marasas, W. F. O., McLeod, A., Stander, M. A., and Viljoen, A. 2012. Resistance in maize inbred lines to Fusarium verticillioides and fumonisin accumulation in South Africa. Plant Dis. 96:881-888.

Fusarium ear rot of maize, caused by Fusarium verticillioides, is an important disease affecting maize production worldwide. Apart from reducing yield and grain quality, F. verticillioides produces fumonisins which have been associated with mycotoxicoses of animals and humans. Currently, no maize breeding lines are known with resistance to F. verticillioides in South Africa. The objective of this study, therefore, was to evaluate 24 genetically diverse maize inbred lines as potential sources of resistance to Fusarium ear rot and fumonisin accumulation in field trials at Potchefstroom and Vaalharts in South Africa. After artificial silk channel inoculation with $F$. verticillioides, Fusarium ear rot development was determined at harvest and fumonisins $\mathrm{B}_{1}, \mathrm{~B}_{2}$, and $\mathrm{B}_{3}$ quantified. A significant inbred line by location effect was observed

to be consistently resistant across both locations. The individual inbred lines also differed considerably in fumonisin accumulation between Potchefstroom and Vaalharts, with differentiation between susceptible and potentially resistant inbred lines only being possible at Vaalharts. A greenhouse inoculation trial was then also performed on a subset of potentially resistant and highly susceptible lines. The inbred lines CML 390, CML 444, CML 182, VO 617Y-2, and RO 549 W consistently showed a low Fusarium ear rot $(<5 \%)$ incidence at both Potchefstroom and Vaalharts and in the greenhouse. Two of these inbred lines, CML 390 and CML 444, accumulated fumonisin levels $<5 \mathrm{mg} \mathrm{kg}^{-1}$. These lines could potentially act as sources of resistance for use within a maize breeding program.
\end{abstract} for Fusarium ear rot severity $(P \leq 0.001)$, although certain lines proved
Fusarium spp. are known as common fungal pathogens of maize, causing ear, stalk, and root rots (19). The most important species responsible for Fusarium ear rot are Fusarium verticillioides (Sacc.) Nirenberg, F. proliferatum (Matsush.) Nirenberg, and $F$. subglutinans (Wollenw. \& Reinking) P.E. Nelson, Toussoun and Marasas, while $F$. graminearum Schwabe is responsible for Gibberella ear rot (18). F. verticillioides is the predominant Fusarium $\mathrm{sp}$. associated with maize grain in South Africa $(21,24)$ and can infect the maize plant at all developmental stages, in some cases without causing symptoms (20). When infection develops into Fusarium ear rot, the disease becomes of particular concern to maize producers and the processing industry, not only because it reduces grain quality (1) but also because $F$. verticillioides produces toxic secondary metabolites in maize kernels, called fumonisins (15).

Fumonisins compose a family of related metabolites that consists of at least 28 analogues. The most common analogues that contaminate maize-based foods and feeds and that result in mycotoxicoses of animals and humans $(15,34)$ are fumonisins $B_{1}, B_{2}$, and $B_{3}(26)$. Due to their risks to human and animal health, guidelines for fumonisin content in maize products intended for food and animal feed have been implemented in a number of countries (35).

In southern Africa, legislation on tolerable levels for fumonisins generally does not exist or is not enforced $(31,36)$. Therefore, a

Corresponding author: A. Viljoen, E-mail: altus@sun.ac.za

Current address of I. M. Small: Department of Plant Pathology and PlantMicrobe Biology, Cornell University, Ithaca, NY 14850.

Accepted for publication 20 December 2011.

http://dx.doi.org/10.1094/PDIS-08-11-0695

(C) 2012 The American Phytopathological Society substantial portion of the maize crop in many parts of southern Africa could be affected when environmental conditions favor fumonisin accumulation in grain. Thus, there is a need to control ear rots of maize to obtain good quality grain and to reduce the potential health effects associated with consumption of fumonisincontaminated grain. The most effective approach to controlling $F$. verticillioides ear rots and minimizing the risk of fumonisin accumulation in grain is the development of host resistance (6). Host resistance would provide producers with environmentally sound and economical control of Fusarium ear rot and fumonisins.

Genetic variation for resistance to Fusarium ear rot has been investigated for a number of decades $(4,6,8,11,12,14,23,25,29)$. Heritable resistance has been identified in maize $(1,6)$ but no highly resistant genotypes suited to the production regions in southern Africa, where maize is the preferred staple food, are known $(2,10)$.

The potential problems associated with Fusarium ear rot and fumonisin contamination of maize could be averted by proactively screening maize cultivars for resistance to $F$. verticillioides and fumonisin. In addition, sources of resistance should be identified in maize germplasm, preferably in locally adapted inbred lines, for use in breeding programs. Existing cultivars in South Africa are not known to have sufficient resistance to Fusarium ear rot or fumonisin contamination (25), and limited information is available for inbred lines used in South Africa. The objective of this study, therefore, was to evaluate maize inbred lines used by the South African Agricultural Research Council's Grain Crops Institute (ARC-GCI) for resistance to this pathogen and the fumonisins it produces. Inbred lines possessing resistance to Fusarium ear rot and fumonisin accumulation would be valuable in a breeding program to develop resistant maize cultivars that can be grown by farmers.

\section{Materials and Methods}

Plant material evaluated. In total, 24 inbred lines selected by plant breeders from the ARC-GCI for their genetic diversity and positive agronomic traits were evaluated for resistance to Fusarium 
ear rot and fumonisin accumulation caused by $F$. verticillioides. The inbred lines consisted of both yellow and white maize, as well as normal and high-lysine maize (Table 1). The inbred lines were planted at two field sites in maize-producing regions of South Africa. Based on their resistance or susceptibility to Fusarium ear rot in the 2007-08 field trials, 12 lines were chosen for further evaluation under controlled greenhouse conditions at Welgevallen experimental farm, Stellenbosch University (Table 1).

Preparation of fungal inoculum. Inoculum for the artificial inoculation of field and greenhouse trials was prepared using a culture of F. verticillioides (Medical Research Council [MRC] 826). This isolate was originally obtained from infected maize in the former Transkei region of South Africa, and is known as a wellcharacterized, prolific producer of fumonisin $\mathrm{B}_{1}(26)$. Isolate MRC 826 was grown in Armstrong liquid medium (3) in Erlenmeyer flasks incubated at $25^{\circ} \mathrm{C}$ in a rotary shaker at 100 revolutions $\mathrm{min}^{-1}$. After 4 days, the fungal spores were collected by pouring them through two layers of sterile cheesecloth into a centrifuge bottle. The suspension was then spun at 3,500 rcf for $10 \mathrm{~min}$, the supernatant was removed, and the conidia were washed twice in deionized, autoclaved water. The conidial pellet was suspended in sterile distilled water and adjusted to a final concentration of $2 \times 10^{6}$ conidia $\mathrm{ml}^{-1}$. Tween 20 surfactant (polyoxyethylene 20-sorbitan monolaurate; Fischer Biotech, Fairlawn, NJ) was added to the conidial suspension before inoculation of maize ears, as a surfactant, at a rate of 3 drops liter ${ }^{-1}$.

Field evaluation. A field trial, consisting of 24 inbred lines, was planted in the 2006-07 season at Potchefstroom, Northwest Province in South Africa (grid reference $26^{\circ} 44^{\prime} \mathrm{S}, 27^{\circ} 05^{\prime} \mathrm{E}$; altitude, $1,355 \mathrm{~m}$ ), and natural infection by $F$. verticillioides was allowed to take place. Because the trial was situated within a high infection area for Fusarium ear rot, it was decided not to artificially inoculate the trial. In 2007-08, the field trials were repeated at two locations, one at Potchefstroom and the other at Vaalharts (grid reference $27^{\circ} 57^{\prime} \mathrm{S}, 24^{\circ} 50^{\prime} \mathrm{E}$; altitude, $1,180 \mathrm{~m}$ ), in the Northern Cape Province of South Africa. This time, however, the trials were artificially inoculated because of insufficient disease development in the previous planting season. The Potchefstroom and Vaalharts sites have different climatic conditions and, therefore, weather data was obtained from the ARC's weather stations located at the respective field sites.
Agricultural practices at the Potchefstroom and Vaalharts locations were similar. The land was treated with pre-emergence herbicide bendioxide at $480 \mathrm{~g} \mathrm{liter}^{-1}$ (Basagran) and post-emergence with halosulfuron-methyl at $750 \mathrm{~g} \mathrm{~kg}^{-1}$ (Servian $75 \mathrm{WG}$ ) to control weeds. The trials were fertilized with 2:3:2 N:P:K at a rate of 200 $\mathrm{kg} \mathrm{ha}^{-1}$ prior to planting. Maize seeds were planted manually, two seeds per planting hole, in double-row experimental units (plots) that were $5 \mathrm{~m}$ long, with 17 plants per row, and later thinned to one plant per planting hole. The intra-row spacing was $0.3 \mathrm{~m}$ with inter-row spacing of $1 \mathrm{~m}$ in a randomized complete block design with four replications per inbred line. The Potchefstroom trial was conducted under dryland conditions, with moisture stress being monitored and supplemental irrigation applied for the duration of the trial. In contrast, the trial in Vaalharts was irrigated on a weekly basis via flood irrigation. The trials were top-dressed with LAN 28, by broadcast method, at the eighth leaf stage (V8; 27). At approximately the 10th leaf stage, both trials were treated for stalk-borer infestation with $\beta$-cyfluthrin at $0.5 \mathrm{~g} \mathrm{~kg}^{-1}$ (Bulldock $0.05 \mathrm{GR}$ ). Application of $40 \mathrm{~g}$ per $100-\mathrm{m}$ row was made directly into the whorl of the maize plants by hand.

Greenhouse evaluation. An artificially inoculated, hydroponic greenhouse trial was conducted to evaluate 12 inbred lines (Table 1) under conditions where nutrient and water availability could be controlled. Temperature and humidity were not strictly controlled in the greenhouse but a pad and fan cooling system was used to prevent the temperature exceeding $30^{\circ} \mathrm{C}$. Before the onset of the trial, the greenhouse was surface sterilized by spraying all surfaces with dimethyl didecyl ammonium chloride at $120 \mathrm{~g} \mathrm{liter}^{-1}$ (Sporekill) at a rate of $1 \mathrm{ml} \mathrm{liter}^{-1}$. Seed from the inbred lines was soaked in distilled water for $4 \mathrm{~h}$ before undergoing a hot water treatment $\left(60^{\circ} \mathrm{C}\right.$ for $\left.5 \mathrm{~min}\right)$ in order to disinfect the seed (13). The seed was then placed on sterile paper towels and incubated at $27^{\circ} \mathrm{C}$. After 5 days, seed that had successfully germinated with no sign of fungal infection were planted directly into 15 -liter greenhouse plant bags filled with coconut coir growth medium (Vegtech 2000, Cape Town, South Africa). The coconut coir medium was prepared by soaking the dry blocks in water amended with $\mathrm{CaNO}_{3}(1 \mathrm{~kg}$ per 1,000 liters), $\mathrm{MgS}$ ( $0.3 \mathrm{~kg}$ per 1,000 liters), and dimethyl didecyl ammonium chloride (120 g per 1,000 liters) for 3 days before being used to fill the plant bags. The plastic plant bags were black on the interior and white on the exterior to reduce heat absorption.

Table 1. Description and identities of maize inbred lines evaluated for resistance to Fusarium ear rot and fumonisin accumulation in field and greenhouse trials in South Africa

\begin{tabular}{|c|c|c|c|c|}
\hline Inbred line number & Identity of inbred line & Source $^{y}$ & Kernel color & Protein content \\
\hline $1^{\mathrm{z}}$ & CML 390 & CIMMYT-Zimbabwe & White & Normal \\
\hline $2^{z}$ & CML 395 & CIMMYT-Zimbabwe & White & Normal \\
\hline 3 & CML 442 & CIMMYT-Zimbabwe & White & Normal \\
\hline $4^{z}$ & CML 444 & CIMMYT-Zimbabwe & White & Normal \\
\hline 5 & CML 488 & CIMMYT-Zimbabwe & White & Normal \\
\hline 6 & CZL 03012 & CIMMYT-Zimbabwe & White & Normal \\
\hline $7^{z}$ & CML 182 & CIMMYT-Zimbabwe & White & High lysine \\
\hline 8 & CML 176-2 & CIMMYT-Zimbabwe & White & High lysine \\
\hline 9 & KO 800Y & ARC-GCI-South Africa & Yellow & High lysine \\
\hline $10^{\mathrm{z}}$ & VO $617 Y-2$ & ARC-GCI-South Africa & Yellow & High lysine \\
\hline 11 & UO $718 Y-1$ & ARC-GCI-South Africa & Yellow & High lysine \\
\hline $12^{z}$ & RO $424 \mathrm{~W}$ & ARC-GCI-South Africa & White & High lysine \\
\hline 13 & RO $450 \mathrm{~W}$ & ARC-GCI-South Africa & White & High lysine \\
\hline $14^{\mathrm{z}}$ & RO 544 W & ARC-GCI-South Africa & White & High lysine \\
\hline $15^{\mathrm{z}}$ & RO 549 W & ARC-GCI-South Africa & White & High lysine \\
\hline 16 & U 2540 & ARC-GCI-South Africa & White & Normal \\
\hline 17 & K64R-22 & ARC-GCI-South Africa & White & Normal \\
\hline $18^{\mathrm{z}}$ & L116W & ARC-GCI-South Africa & White & Normal \\
\hline $19^{\mathrm{z}}$ & I $137 \mathrm{tnW}$ & ARC-GCI-South Africa & White & Normal \\
\hline 20 & R119W & ARC-GCI-South Africa & White & Normal \\
\hline $21^{z}$ & M162W & ARC-GCI-South Africa & White & Normal \\
\hline 22 & CBS 3-11-3-B & ARC-GCI-South Africa & White & Normal \\
\hline $23^{z}$ & $\mathrm{R} 2565 \mathrm{Y}$ & ARC-GCI-South Africa & Yellow & Normal \\
\hline 24 & I-B & ARC-GCI-South Africa & Yellow & Normal \\
\hline
\end{tabular}

y ARC-GCI: Agricultural Research Council's Grain Crops Institute.

${ }^{\mathrm{z}}$ Inbred lines evaluated in greenhouse trials at Stellenbosch University. 
Before planting, the medium in the plant bags was rinsed with water until the electrical conductivity of the drainage water was below 0.7 . The trial layout was a completely randomized design with four replicates and seven plants per replicate for each line.

The seedlings were irrigated in their plant bags using an automated hydroponic nutrient irrigation system. Initially, the seedlings were each given a daily irrigation of approximately $500 \mathrm{ml}$ of nonfertilized water for a period of 1 week. From weeks two to five, a modified Steiner nutrient solution (33), as described by Combrink (7), with an electrical conductivity (EC) of 1.5 at a $\mathrm{pH}$ of 6.5 was used to irrigate the seedlings. The plants received a minimum of five daily irrigations, sufficient to result in a total of $30 \%$ drainage over the entire day, to prevent the accumulation of salts in the medium. From week five onward, the nutrient solution was adjusted to an EC of 2.5 at a $\mathrm{pH}$ of 6.5. The drainage was monitored on a regular basis and the irrigations adjusted to account for changing weather conditions.

Inoculation of maize ears. Ears were inoculated using a cattle inoculator fitted with an $18 \mathrm{G} \times 1.5$-in. (1.20-by-38-mm) Terumo needle (sterile, nontoxic, and nonpyrogenic). Conidial suspensions $(2 \mathrm{ml})$ were injected down the silk channel of primary ears of all plants at the blister (R2) growth stage (27) based on the inoculation method used by Afolabi et al. (1). Inoculated ears were marked with nylon twine for identification at harvest. The inoculation procedure and timing were identical for both field and greenhouse trials.

Disease assessment. The inoculated maize ears (marked with nylon twine) were handpicked when grain was dry (between 12 and $18 \%$ kernel moisture), dehusked, and evaluated for severity of ear rot symptoms. Disease severity was assessed by estimating the percentage of each ear covered by visible symptoms of infection, such as brown, pink, or reddish discoloration of kernels, and pinkish or white mycelial growth (6).

Grain processing. After disease assessment, the ears collected in the field were dried in a ventilated glasshouse to approximately $14 \%$ grain moisture content, while those collected in the greenhouse were dried to $12 \%$ in a forced-air oven at between 50 and $60^{\circ} \mathrm{C}$. Several hours at temperatures between 50 and $60^{\circ} \mathrm{C}$ have been shown to have no significant effect on fumonisin concentration in grain (9). Grain was hand shelled and bulked by plot. A sample of $250 \mathrm{~g}$ was taken from each bulked sample and ground using a Cyclotech sample mill (Foss Tecator, Hoganas, Sweden) to pass through a $1-\mathrm{mm}$ mesh. Ground samples were then stored at $-20^{\circ} \mathrm{C}$ for fumonisin analysis.

Fumonisin analysis. A 25-g sample of the stored ground grain from each plot was used for fumonisin extraction using the method developed by Shephard et al. (32). The dried sample residue was stored at $-20^{\circ} \mathrm{C}$ for no longer than 1 week before analysis.

Liquid chromatographic tandem mass spectrometry (LCMS/MS) was performed on a Quattro Micro triple quadrupole mass spectrometer from Waters/Micromass (Manchester, UK), equipped with an Alliance 2695 high-performance liquid chromatography system (Waters). The electrospray ionization source was used in the positive mode and the settings were optimized for best sensitivity. The mass spectrometer was operated in MRM mode and a cone voltage of $25 \mathrm{~V}$ was used for all transitions. The following transitions were used: for fumonisin $\mathrm{B}_{1}, 722.4>352.2$ and $722.4>334.4$; and, for fumonisin $\mathrm{B}_{2}$ and $\mathrm{B}_{3}, 706.0>318.4$ and $706.0>336.4$, respectively, at a collision energy of $40 \mathrm{eV}$. Separation was achieved on a SunFire C18 analytical column $(3.5 \mu \mathrm{m}$, 150 by $4.6 \mathrm{~mm}$, with guard column; Waters, Milford, MA). The mobile phase consisted of $1 \%$ formic acid (solvent A) and methanol (solvent B) and a flow rate of $1 \mathrm{ml} \mathrm{min}^{-1}$ was used. After an isocratic step of $62 \% \mathrm{~B}$ for $3 \mathrm{~min}$, it was linearly increased to $100 \% \mathrm{~B}$ over $2.1 \mathrm{~min}$ and held constant for $1 \mathrm{~min}$ followed by reequilibration for $7.9 \mathrm{~min}$. The retention times under these conditions were $2.65 \mathrm{~min}$ for fumonisin $\mathrm{B}_{1}, 5.98 \mathrm{~min}$ for fumonisin $\mathrm{B}_{2}$, and 4.61 min for fumonisin $B_{3}$.

Standards of fumonisin $\mathrm{B}_{1}(10 \mathrm{mg}), \mathrm{B}_{2}(10 \mathrm{mg})$, and $\mathrm{B}_{3}(1 \mathrm{mg})$, $>95 \%$ pure, were obtained from the MRC Program on Mycotoxins and Experimental Carcinogenesis, Tygerberg, South Africa. Fumonisin calibration standards ranged between 0.05 and $20 \mathrm{mg} \mathrm{kg}^{-1}$ for $\mathrm{FB}_{1}$ and $\mathrm{FB}_{2}$, and between 0.005 and $2 \mathrm{mg} \mathrm{kg}^{-1}$ for $\mathrm{FB}_{3}$. Purified sample residue was reconstituted in $1 \mathrm{ml}$ of $\mathrm{ACN} /$ water (50/50 [vol/vol]) and $5 \mu \mathrm{l}$ of the solution was injected into the LC-MS/MS system. Purified sample residue was reconstituted in ACN/water because fumonisins are more stable in this solvent than in methanol mixtures (5). The limits of quantification for $\mathrm{FB}_{1}, \mathrm{FB}_{2}$, and $\mathrm{FB}_{3}$ were $0.02,0.002$, and $0.02 \mathrm{mg} \mathrm{kg}^{-1}$, respectively. The extraction recovery rate ranged between 60 and $65 \%$ for each compound from naturally contaminated samples.

Statistical analysis. Effects of field location and inbred lines on severity of Fusarium ear rot and fumonisin concentration in grain were analyzed using STATISTICA (data analysis software system, version 8.0; StatSoft, Inc., Tulsa, OK). A mixed-model approach was used, where replications were considered random terms and location and inbred lines were considered fixed effects. Results for individual locations were presented separately if a significant inbred-location effect was detected for either fumonisin contamination or ear rot severity. Significant differences between inbred lines were determined with Fisher's protected least significant difference test. To investigate the relative performance of inbred lines across locations, nonparametric Spearman rank correlation coefficients were determined for both ear rot severity and fumonisin concentration using STATISTICA based on untransformed means. Relationships among ear rot severity and fumonisin concentration were studied using Pearson as well as nonparametric Spearman rank correlation coefficients based on untransformed means.

For the greenhouse trial, effects of inbred lines on Fusarium ear rot, fumonisin concentration in grain, and yield were analyzed using a one-way analysis of variance in STATISTICA. In the statistical model, replications were considered random terms and inbred lines were considered fixed effects. The relationships among ear rot severity and fumonisin concentration were investigated as for the field trial.

\section{Results}

Field evaluation. In the 2006-07 maize planting season, $F$. verticillioides infection took place under natural conditions, with mean Fusarium ear rot symptom ratings of $0.1 \pm 0.1 \%$ to a maximum of $4.2 \pm 8.3 \%$, which prevented the differentiation of resistant from susceptible inbred lines (results not presented). Fumonisin data from the trial supported this conclusion.

Sufficient Fusarium ear rot developed and fumonisin was produced in maize kernels in the 2007-08 planting season following artificial field inoculation with $F$. verticillioides. The mean Fusarium ear rot severity for the 24 inbred lines was $0.1 \pm 0.1$ to $26.5 \pm$ $7.8 \%$ at Potchefstroom and $0.2 \pm 0.2$ to $24.0 \pm 9.2 \%$ at Vaalharts (Table 2). Mean total fumonisin content $\left(\mathrm{B}_{1}, \mathrm{~B}_{2}\right.$, and $\left.\mathrm{B}_{3}\right)$ in maize inbred lines was $0.5 \pm 0.1$ to $7.5 \pm 5.2 \mathrm{mg} \mathrm{kg}^{-1}$ at Potchefstroom and $2.7 \pm 0.8$ to $61.1 \pm 33.5 \mathrm{mg} \mathrm{kg}^{-1}$ at Vaalharts. A significant inbred line-location interaction effect was observed for both Fusarium ear rot severity and fumonisin contamination $(P \leq 0.001)$.

The average visual rating of Fusarium ear rot infection of maize ears at Potchefstroom and Vaalharts was 6.7 and 5.0\%, respectively, suggesting similar levels of disease development at the two locations (Table 2). Although most of the inbred lines showed comparable responses to Fusarium ear rot across locations, as supported by a Spearman correlation value of $r=0.61(P \leq 0.001)$, some lines, such as lines $5,14,19,21$, and 23 , showed significantly different responses to the disease $(P \leq 0.05)$. For instance, the mean visual rating for line 5 at Potchefstroom was significantly higher $(11 \%)$ than at Vaalharts $(2.7 \%)$, exemplifying the highly significant inbred line-location interaction effect $(P \leq 0.001)$. Significant differences in response of inbred lines to Fusarium ear rot also occurred within field locations. At Potchefstroom, six inbred lines (lines $1,4,7,10,13$, and 15$)$ had significantly $(P \leq 0.05)$ less Fusarium ear rot $(0.1$ to $2.4 \%)$ than the lines with the highest disease severity (lines 3, 5, 9, 14, 21, and 23; 9.6 to 26.5\%) (Table 2). At Vaalharts, the 12 inbred lines that showed the lowest ear rot 
severity (lines $1,4,5,6,7,8,10,13,15,17,20$, and $22 ; 0.2$ to $2.9 \%$ ) differed significantly $(P \leq 0.05)$ from those displaying the highest severities (lines 3 and 19;11.7 to 24\%) (Table 2). Maize inbred lines $1,4,7,10,13$, and 15 were the only lines that consistently grouped into the low Fusarium ear rot severity group for both field locations, with mean visual ratings for these lines of 0.1 to $2.4 \%$.

The individual inbred lines differed considerably in their fumonisin accumulation between Potchefstroom and Vaalharts, as indicated by a significant but poor Spearman rank correlation $(r=$ $0.43, P=0.03)$. For instance, at Potchefstroom, line 2 accumulated significantly less fumonisin $\left(0.7 \mathrm{mg} \mathrm{kg}^{-1}\right)$ than at Vaalharts $(27.6$ $\mathrm{mg} \mathrm{kg}^{-1}$ ) (Table 2). This location effect was also indicated by the lower average fumonisin concentration at Potchefstroom $(2.7 \mathrm{mg}$ $\left.\mathrm{kg}^{-1}\right)$ compared with Vaalharts $\left(17.2 \mathrm{mg} \mathrm{kg}^{-1}\right)(P=0.002$; Table 2). At Potchefstroom, no significant differences between inbred lines for mean fumonisin content were observed. Some of the inbred lines at Vaalharts, however, differed significantly from each other in fumonisin content, with inbred lines $1,3,4,6,16,17$, and 20 containing significantly lower levels of fumonisin $(2.7$ to $5.3 \mathrm{mg}$ $\mathrm{kg}^{-1}$ ) than lines $2,9,12,18,19,23$, and $24\left(22.7\right.$ to $\left.61.1 \mathrm{mg} \mathrm{kg}^{-1}\right)$ (Table 2).

A significant correlation was observed between Fusarium ear rot and fumonisin content at Potchefstroom (Pearson correlation of $r=$ $0.54, P \leq 0.01$; Spearman correlation of $r=0.59, P \leq 0.01)$ and Vaalharts (Pearson correlation of $r=0.72, P \leq 0.01$; Spearman correlation of $r=0.62, P \leq 0.01)$. This finding is exemplified by line 1 , which had a disease severity of $0.1 \%$ and fumonisin content of $0.7 \mathrm{mg} \mathrm{kg}^{-1}$ at Potchefstroom, or line 19 , with a disease severity of $24 \%$ and fumonisin content of $61.1 \mathrm{mg} \mathrm{kg}^{-1}$ at Vaalharts. Some lines did, however, record relatively high disease severity and low fumonisin content, such as line 3 at Vaalharts, which had a visual rating of $12 \%$ and fumonisin contamination level of $5 \mathrm{mg} \mathrm{kg}^{-1}$; or low disease severity and high fumonisin content, exemplified by line 24 at Vaalharts, which had a visual rating of $4 \%$ while still containing $34 \mathrm{mg} \mathrm{kg}^{-1}$ of fumonisin (Table 2; Fig. 1).

Mean monthly temperatures at the two field locations during the 2007-08 season were similar, with a slightly higher average tem- perature at Vaalharts during the growing season (December to July; Fig. 2). The monthly rainfall was higher at Potchefstroom at the start of the growing season (December) and over the inoculation period (February and March). At the Vaalharts location, there was significantly lower rainfall during grain filling (March) when compared with Potchefstroom and slightly higher rainfall during the months of April and May when the grain was drying (Fig. 2).

Greenhouse evaluation. Significant differences in Fusarium ear rot development were found between inbred lines in the greenhouse trial. Lines $1,2,4,7,10,12,14$, and 15 were considered as having low mean Fusarium ear rot severity $(0.4$ to $10.3 \%)$ that differed significantly from lines $18,19,21$, and 23 (17.6 to 46\%) (Table 3; Fig. 3). Fumonisin analysis showed that a group of lines (lines $1,2,4,7,10,12,14,15,21$, and 23) which had lower fumonisin content $\left(0.1\right.$ to $\left.8.9 \mathrm{mg} \mathrm{kg}^{-1}\right)$ differed significantly from the two lines (18 and 19) that had the highest fumonisin content (28.5 to $31.2 \mathrm{mg} \mathrm{kg}^{-1}$ ) (Table 3; Fig. 4).

The response of the inbred lines following artificial inoculation with $F$. verticillioides in the greenhouse correlated well with the response of the same lines when artificially inoculated in the field. Visual rating results of the respective lines correlated well between the greenhouse and Potchefstroom field trial $(r=0.75, P \leq 0.01)$ and between the greenhouse and Vaalharts field trial $(r=0.89, P \leq$ 0.001 ). Toxin rating results for the lines in the greenhouse correlated well with the Potchefstroom field trials $(r=0.79, P \leq 0.001)$ and moderately well between the greenhouse and Vaalharts field trial $(r=0.58, P \leq 0.05)$.

In the greenhouse, a significant correlation was found between Fusarium ear rot severity and fumonisin content (Pearson correlation of $r=0.94, P \leq 0.01$; Spearman correlation of $r=0.92, P \leq$ 0.01). Interestingly, however, line 23 accumulated low levels of fumonisin in the greenhouse despite being highly susceptible to Fusarium ear rot in the greenhouse and field trials.

\section{Discussion}

Maize inbred lines with potential resistance to Fusarium ear rot and fumonisin accumulation, caused by $F$. verticillioides, were

Table 2. Evaluation of 24 maize inbred lines for resistance to Fusarium ear rot and fumonisin accumulation in field trials at Potchefstroom and Vaalharts in the 2007-08 planting season

\begin{tabular}{|c|c|c|c|c|}
\hline \multirow[b]{2}{*}{ Inbred line number } & \multicolumn{2}{|c|}{ Fusarium ear rot severity $(\%)^{x, y}$} & \multicolumn{2}{|c|}{ Fumonisin $\left(\mathrm{mg} \mathrm{kg}^{-1}\right)^{\mathrm{x}, \mathrm{z}}$} \\
\hline & Potchefstroom & Vaalharts & Potchefstroom & Vaalharts \\
\hline 1 & $0.1 \mathrm{a}$ & $0.2 \mathrm{a}$ & $0.7 \mathrm{a}$ & $2.7 \mathrm{a}$ \\
\hline 2 & $6.4 \mathrm{a}-\mathrm{i}$ & $4.7 \mathrm{a}-\mathrm{h}$ & $0.7 \mathrm{a}$ & $27.6 \mathrm{ef}$ \\
\hline 3 & $9.6 \mathrm{ghi}$ & $11.7 \mathrm{ij}$ & $1.2 \mathrm{a}$ & $5.1 \mathrm{ab}$ \\
\hline 4 & $2.4 \mathrm{a}-\mathrm{f}$ & $1.0 \mathrm{abc}$ & $1.7 \mathrm{a}$ & $4.1 \mathrm{ab}$ \\
\hline 5 & $11.0 \mathrm{hi}$ & $2.7 \mathrm{a}-\mathrm{f}$ & $2.5 \mathrm{a}$ & 13.6 a-e \\
\hline 6 & $5.0 \mathrm{a}-\mathrm{h}$ & $0.7 \mathrm{ab}$ & $2.2 \mathrm{a}$ & $4.3 \mathrm{ab}$ \\
\hline 7 & $0.7 \mathrm{ab}$ & $1.5 \mathrm{a}-\mathrm{e}$ & $1.0 \mathrm{a}$ & $8.6 \mathrm{abc}$ \\
\hline 8 & $4.7 \mathrm{a}-\mathrm{h}$ & $1.2 \mathrm{a}-\mathrm{d}$ & $5.4 \mathrm{ab}$ & $9.4 \mathrm{abc}$ \\
\hline 9 & $11.0 \mathrm{hi}$ & $8.1 \mathrm{f}-\mathrm{i}$ & $2.8 \mathrm{a}$ & $46.0 \mathrm{gh}$ \\
\hline 10 & $1.4 \mathrm{a}-\mathrm{e}$ & $2.7 \mathrm{a}-\mathrm{f}$ & $1.1 \mathrm{a}$ & $10.8 \mathrm{a}-\mathrm{d}$ \\
\hline 11 & $3.2 \mathrm{a}-\mathrm{g}$ & $6.9 \mathrm{~b}-\mathrm{i}$ & $3.5 \mathrm{ab}$ & $20.4 \mathrm{~b}-\mathrm{f}$ \\
\hline 12 & $3.3 \mathrm{a}-\mathrm{g}$ & $6.2 \mathrm{a}-\mathrm{i}$ & $1.4 \mathrm{a}$ & $26.7 \mathrm{def}$ \\
\hline 13 & $2.2 \mathrm{a}-\mathrm{f}$ & $2.4 \mathrm{a}-\mathrm{f}$ & $0.9 \mathrm{a}$ & $12.0 \mathrm{a}-\mathrm{e}$ \\
\hline 14 & 26.51 & $7.7 \mathrm{e}-\mathrm{i}$ & $5.5 \mathrm{abc}$ & 16.6 a-e \\
\hline 15 & $2.0 \mathrm{a}-\mathrm{f}$ & $0.7 \mathrm{ab}$ & $0.9 \mathrm{a}$ & $6.4 \mathrm{abc}$ \\
\hline 16 & $3.6 \mathrm{a}-\mathrm{g}$ & $4.4 \mathrm{a}-\mathrm{h}$ & $0.5 \mathrm{a}$ & $5.1 \mathrm{ab}$ \\
\hline 17 & $4.1 \mathrm{a}-\mathrm{g}$ & $2.9 \mathrm{a}-\mathrm{f}$ & $3.8 \mathrm{ab}$ & $5.2 \mathrm{ab}$ \\
\hline 18 & $4.3 \mathrm{a}-\mathrm{g}$ & $6.2 \mathrm{a}-\mathrm{i}$ & $6.0 \mathrm{abc}$ & $22.7 \mathrm{c}-\mathrm{f}$ \\
\hline 19 & $7.7 \mathrm{~d}-\mathrm{i}$ & $24.0 \mathrm{kl}$ & $7.5 \mathrm{abc}$ & $61.1 \mathrm{~h}$ \\
\hline 20 & $6.9 \mathrm{~b}-\mathrm{i}$ & $1.7 \mathrm{a}-\mathrm{f}$ & $1.8 \mathrm{a}$ & $5.3 \mathrm{ab}$ \\
\hline 21 & $18.8 \mathrm{k}$ & $7.5 \mathrm{c}-\mathrm{i}$ & $5.2 \mathrm{ab}$ & $6.3 \mathrm{abc}$ \\
\hline 22 & $4.6 \mathrm{a}-\mathrm{h}$ & $2.8 \mathrm{a}-\mathrm{f}$ & $1.2 \mathrm{a}$ & $13.0 \mathrm{a}-\mathrm{e}$ \\
\hline 23 & $17.7 \mathrm{jk}$ & $7.9 \mathrm{e}-\mathrm{i}$ & $5.2 \mathrm{ab}$ & $45.4 \mathrm{gh}$ \\
\hline 24 & $4.7 \mathrm{a}-\mathrm{h}$ & $4.2 \mathrm{a}-\mathrm{g}$ & $2.5 \mathrm{a}$ & $34.2 \mathrm{fg}$ \\
\hline Mean & 6.7 & 5.0 & 2.7 & $17.2^{\circ}$ \\
\hline
\end{tabular}

${ }^{\mathrm{x}}$ For each variable (Fusarium ear rot severity or fumonisin content), means followed by the same letter do not differ significantly according to Fisher's least significant difference test $(P \leq 0.05)$

y Percentage of maize ear showing visual symptoms of Fusarium ear rot; mean of disease severity (\%) for four field plots.

${ }^{\mathrm{z}}$ Fumonisin concentration $=$ total of $\mathrm{FB}_{1}+\mathrm{FB}_{2}+\mathrm{FB}_{3}$; mean of fumonisin concentration for four field plots 
identified from well-adapted breeding material used in South Africa. This is of great significance, because $F$. verticillioides is known to be the most common fungal pathogen associated with Fusarium ear rot in the country and because existing cultivars are not known to have sufficient resistance to Fusarium ear rot or fumonisin contamination (25). Maize genotypes adapted to Central and West Africa with resistance to Fusarium ear rot and fumonisin contamination have been identified by Afolabi et al. (1). These genotypes, however, are better adapted to tropical conditions and are not necessarily suited to the dry temperate conditions in Southern Africa.

None of the inbred lines evaluated in this study were completely resistant to $F$. verticillioides or the fumonisins it produces, which is in agreement with previous studies $(6,22)$. However, several inbred lines, including $1,4,7,10$, and 15 , were found to have consistently low Fusarium ear rot at both the Potchefstroom and Vaalharts field locations and in the greenhouse. Additionally, certain lines were identified that consistently accumulated low fumonisin levels, such as lines 1 and 4 . These lines could potentially act as sources of resistance for use within a maize resistance breeding program.

Significant genotype-location interactions were observed for the inbred lines evaluated. Genotype-location interactions for resistance to Fusarium ear rot and fumonisin have been previously recorded $(28,30)$. Due to the nature of plant diseases, successful infection of the host and subsequent production of mycotoxins is dependent on prevailing environmental conditions, susceptibility of the plant host to the pathogen, as well as insect vector activity under some circumstances (17). Further, it has been documented that maize genotypes grown outside of their normal production zones are likely to be more susceptible to Fusarium ear rot and fumonisin contamination (30). For these reasons, it is important that locally adapted material be used in breeding programs, and that the potentially resistant lines are further evaluated over an extended range of conditions, representative of the localities where they will eventually be grown, to further confirm their resistant status.

A significant correlation between Fusarium ear rot rating and fumonisin concentration in the grain was observed in the field trials. Some of the inbred lines, however, were recorded as having severe ear rot but low fumonisin concentrations. Two possible explanations can be provided: (i) in some plots containing severely rotten ears, much of the kernel tissue was so badly destroyed that it barely contributed to the ground grain sample from which the fumonisin concentration was measured; and (ii) the visual rating was unable to discriminate between visual disease symptoms caused by nonfumonisin-producing fungal species, resulting in high visual rating and low fumonisin concentration. Conversely, outliers were ob-
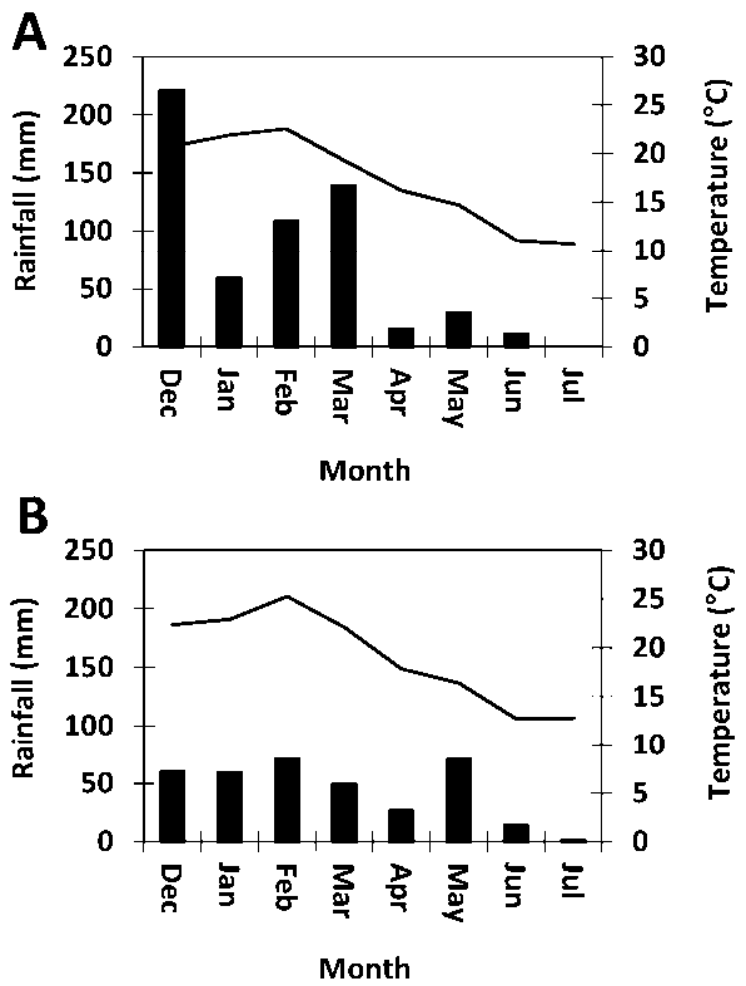

Fig. 2. Weather data recorded from Agricultural Research Council (ARC) weather stations for the 2007-08 season at A, Potchefstroom and B, Vaalharts in South Africa. Line and bar series show mean monthly temperature and total monthly rainfall, respectively, for the growing season.

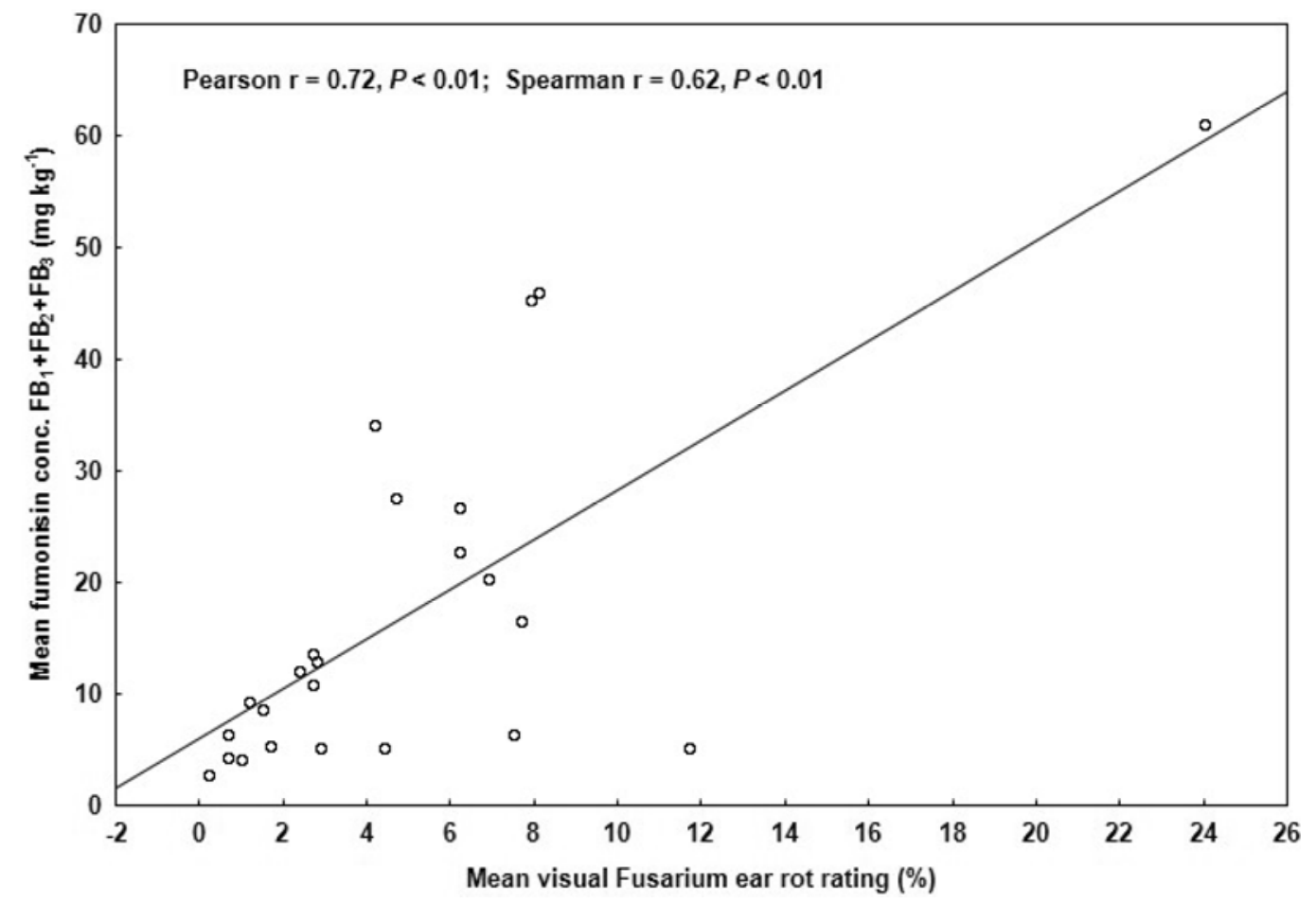

Fig. 1. Comparison of mean visual Fusarium ear rot ratings with mean fumonisin content for 24 maize inbred lines grown at Vaalharts in South Africa. 
served with low ear rot rating but high fumonisin concentrations. Munkvold and Desjardins (19) previously suggested that fumonisin could accumulate in kernels with minimal ear rot. The occurrence of such outliers suggests that fumonisin analyses are necessary when evaluating maize resistance. The cost and time involved in laboratory analyses of fumonisin concentration, however, is prohibitive when conducting large-scale trials. Robertson-Hoyt et al. (28) studied the heritability and correlation of Fusarium ear rot resistance and fumonisin contamination resistance in two maize populations and found that, due to the moderate to high heritability and strong genetic correlation between ear rot and toxin resistance, selection for resistance to ear rot should result in lines with greater

Table 3. Evaluation of 12 maize inbred lines for resistance to Fusarium ear rot and fumonisin accumulation in a greenhouse trial ${ }^{\mathrm{x}}$

\begin{tabular}{lcc}
\hline Inbred line number & $\begin{array}{c}\text { Fusarium ear rot } \\
\text { severity }(\boldsymbol{\%})^{\mathbf{x}, \mathbf{y}}\end{array}$ & $\begin{array}{c}\text { Fumonisin } \\
\left(\mathbf{m g ~ k g}^{-1}\right)^{\mathbf{x}, \mathbf{Z}}\end{array}$ \\
\hline 1 & $1.2 \mathrm{a}$ & $0.1 \mathrm{a}$ \\
2 & $3.3 \mathrm{a}$ & $1.1 \mathrm{a}$ \\
4 & $0.4 \mathrm{a}$ & $0.5 \mathrm{a}$ \\
7 & $2.9 \mathrm{a}$ & $1.0 \mathrm{a}$ \\
10 & $2.8 \mathrm{a}$ & $1.1 \mathrm{a}$ \\
12 & $8.4 \mathrm{ab}$ & $5.6 \mathrm{a}$ \\
14 & $10.3 \mathrm{ab}$ & $5.1 \mathrm{a}$ \\
15 & $3.1 \mathrm{a}$ & $1.5 \mathrm{a}$ \\
18 & $36.7 \mathrm{~d}$ & $28.5 \mathrm{~b}$ \\
19 & $46.0 \mathrm{~d}$ & $31.2 \mathrm{~b}$ \\
21 & $17.6 \mathrm{bc}$ & $8.9 \mathrm{a}$ \\
23 & $22.0 \mathrm{c}$ & $2.6 \mathrm{a}$ \\
Mean & 12.9 & 7.3 \\
\hline
\end{tabular}

${ }^{\mathrm{x}}$ For each variable (Fusarium ear rot severity or fumonisin content), means followed by the same letter do not differ significantly according to Fisher's least significant difference test $(P \leq 0.05)$.

y Percentage of maize ear showing visual symptoms of Fusarium ear rot; mean of disease severity $(\%)$ for four experimental replications (containing seven plants each).

${ }^{\mathrm{z}}$ Fumonisin concentration $=$ total of $\mathrm{FB}_{1}+\mathrm{FB}_{2}+\mathrm{FB}_{3}$; mean of fumonisin concentration from four experimental reps (grain from seven plants pooled for each replication). resistance to fumonisin contamination. Nonetheless, later generation lines selected for reduced ear rot should be evaluated for low fumonisin concentration directly to verify that resistance has been identified.

A higher average fumonisin concentration was observed at the Vaalharts than at the Potchefstroom location in spite of similar average Fusarium ear rot ratings. At the Vaalharts location, there was significantly lower rainfall during grain filling (March) when compared with Potchefstroom, with dry periods before or during grain filling known to favor more severe Fusarium ear rot and higher levels of fumonisins (30). The low rainfall at Vaalharts, however, is unlikely to have resulted in plant stress because these trials were flood irrigated weekly. In vitro studies have shown that optimal conditions for $F$. verticillioides growth and $\mathrm{FB}_{1}$ production are $30^{\circ} \mathrm{C}$ and a water activity of 0.97 , with a dramatic reduction in germination and fumonisin production below a water activity of 0.92 (16). This would suggest that infection may be favored by dry conditions before or during grain filling but that fumonisin production would also be favored in the grain for as long as the grain remains above a water activity of 0.92 . Grain would have a suitable water activity for fumonisin production during the initial drying period in the field, and additional rain after physiological maturity would extend the period suitable for fumonisin production. Slightly higher rainfall at Vaalharts during the months of April and May, when the grain was drying, combined with increased relative humidity due to flood irrigations, may have allowed extended fumonisin accumulation at Vaalharts. Alternatively, the possibility of naturally higher fumonisin-producing inoculum having infected the Vaalharts trial cannot be excluded.

A good correlation was shown between the results from the artificially inoculated greenhouse trial with those of both field locations. The similar responses of the inbred lines evaluated under greenhouse conditions with those of the field trials suggests that greenhouse trials could be used to accelerate progress in the selection of resistant germplasm. In addition, the ability to manipulate environmental conditions, as well as nutrient and water supply in the greenhouse provides an ideal opportunity to investigate the impact of these factors on the resistance of the maize plant and on the ability of the fungus to cause Fusarium ear rot and produce fumonisin.

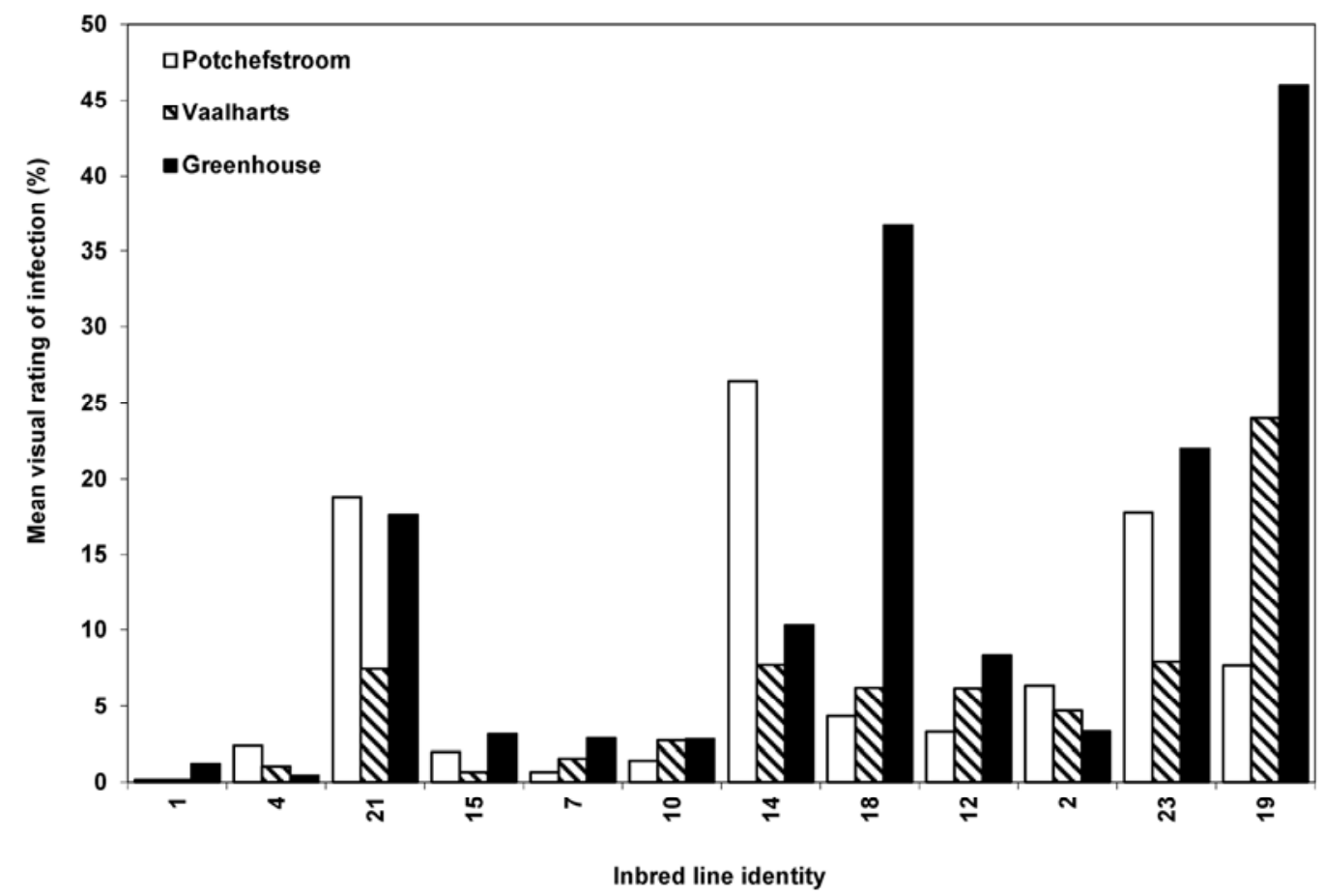

Fig. 3. Mean visual rating of Fusarium ear rot severity for selected inbred lines evaluated in field trials at Vaalharts and Potchefstroom, as well as in greenhouse trials at Stellenbosch, South Africa. 


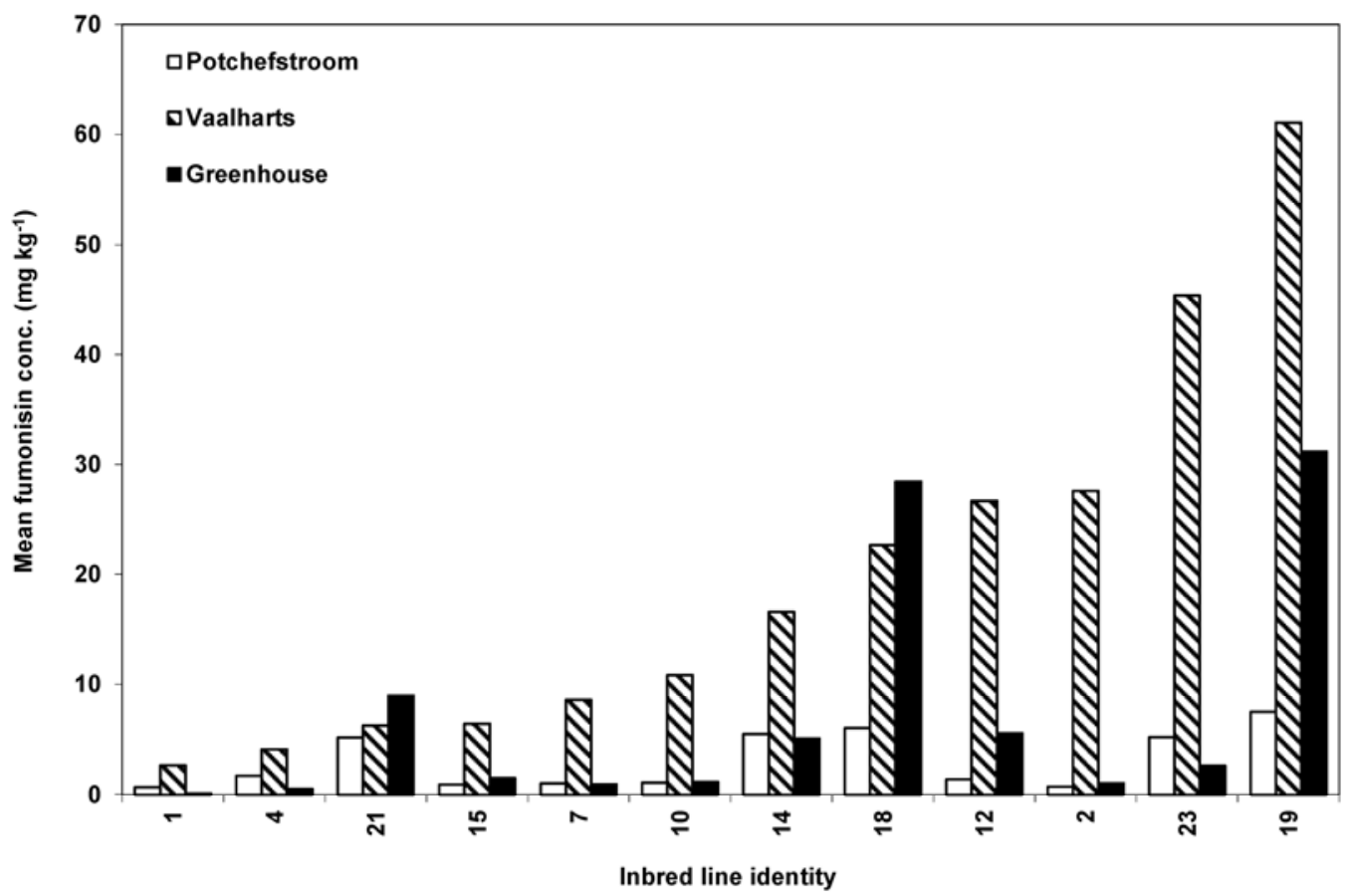

Fig. 4. Mean fumonisin $\left(\mathrm{FB}_{1}+\mathrm{FB}_{2}+\mathrm{FB}_{3}\right)$ concentrations in maize samples from selected inbred lines evaluated in field trials at Vaalharts and Potchefstroom, as well as in greenhouse trials at Stellenbosch, South Africa.

This study is the first to report potentially resistant maize inbred lines locally adapted to southern African production conditions. These inbred lines will not only be useful for the development of resistant commercial cultivars adapted to Southern African production conditions but also may allow insight into the mechanisms involved in resistance to Fusarium ear rot and fumonisin contamination. Similarly, the highly susceptible inbred lines could be used for comparative functional genomics or proteomics, or as susceptible controls in future experiments.

\section{Acknowledgments}

This research was supported by funding from the South African Maize Trust and National Research Foundation: Technology and Human Resources for Industry Programme of South Africa. We thank K. Mashingaidze from the Agricultural Research Council-Grain Crops Institute, South Africa for providing the inbred line seed; H. Vismer from the Medical Research Council-Programme on Mycotoxins and Experimental Carcinogenesis, Tygerberg, South Africa for providing the fungal isolate MRC 826; M. Kidd from the Centre for Statistical Consultation for help with statistical analyses; and A. Belgrove, S. von Diest, and S. Langenhoven for technical assistance.

\section{Literature Cited}

1. Afolabi, C. G., Ojiambo, P. S., Ekpo, E. J. A., Menkir, A., and Bandyopadhyay, R. 2007. Evaluation of maize inbred lines for resistance to Fusarium ear rot and fumonisin accumulation in grain in tropical Africa. Plant Dis. 91:279-286.

2. Aquino, P., Carrión, F., Calvo, R., and Flores, D. 2001. Selected maize statistics. Pages 45-60 in: CIMMYT 1999-2000 World Maize Facts and Trends. Meeting World Maize Needs: Technological Opportunities and Priorities for the Public Sector. P. L. Pingali, ed. CIMMYT, Mexico.

3. Booth, C. 1971. The Genus Fusarium. Commonwealth Mycological Institute, Kew, Surrey, England.

4. Butron, A., Santiago, R., Mansilla, P., Pintos-Varela, C., Ordas, A., and Malvar, R. A. 2006. Maize (Zea mays L.) genetic factors for preventing fumonisin contamination. J. Agric. Food Chem. 54:6113-6117.

5. Cavaliere, C., Foglia, P., Pastorini, E., Samperi, R., and Laganà, A. 2005. Development of a multi-residue method for analysis of major Fusarium mycotoxins in corn meal using liquid chromatography/tandem mass spectrometry. Rapid Commun. Mass Spectrom. 19:2085-2093.

6. Clements, M. J., Maragos, C. A., Pataky, J. K., and White, D. G. 2004. Sources of resistance to fumonisin accumulation in grain and Fusarium ear and kernel rot of corn. Phytopathology 94:251-260.

7. Combrink, N. J. J. 2005. Nutrient Solutions and Greenhouse Management. Combrink Family Trust, Stellenbosch, South Africa.

8. Desjardins, A. E., Plattner, R. D., Stessman, R. J., McCormick, S. P., and Millard, M. J. 2005. Identification and heritability of fumonisin insensitivity in Zea mays. Phytochemistry 66:2474-2480.

9. Dupuy, J., Lebars, P., Boudra, H., and Lebars, J. 1993. Thermostability of fumonisin $\mathrm{B}_{1}$, a mycotoxin from Fusarium moniliforme, in corn. Appl. Environ. Microbiol. 59:2864-2867.

10. FAO. 2007. Food and Agriculture Organization of the United Nations (FAO). November, 2009 11/9/2009.

11. Headrick, J. M., and Pataky, J. K. 1991. Maternal influence on the resistance of sweet corn lines to kernel infection by Fusarium moniliforme. Phytopathology 81:268-274.

12. Kleinschmidt, C. E., Clements, M. J., Maragos, C. M., Pataky, J. K., and White, D. G. 2005. Evaluation of food-grade dent corn hybrids for severity of Fusarium ear rot and fumonisin accumulation in grain. Plant Dis. 89:291297.

13. Leslie, J. F., and Summerell, B. A. 2006. The Fusarium Laboratory Manual. J. F. Leslie, ed. Blackwell Publishing, Oxford.

14. Loesch, P. J., Jr., Foley, D. C., and Cox, D. F. 1976. Comparative resistance of opaque-2 and normal inbred lines of maize to ear-rotting pathogens. Crop Sci. 16:841-842.

15. Marasas, W. F. O. 2001. Discovery and occurrence of the fumonisins: a historical perspective. Environ. Health Perspect. 109:239-243.

16. Marin, S., Magan, N., Belli, A., Ramos, A. J., Canela, R., and Sanchis, V. 1999. Two-dimensional profiles of fumonisin $\mathrm{B}_{1}$ production by Fusarium moniliforme and Fusarium proliferatum in relation to environmental factors and potential for modelling toxin formation in maize grain. Int. J. Food Microbiol. 51:159-167.

17. Munkvold, G. P. 2003. Cultural and genetic approaches to managing mycotoxins in maize. Annu. Rev. Phytopathol. 41:99-116.

18. Munkvold, G. P. 2003. Epidemiology of Fusarium diseases and their mycotoxins in maize ears. Eur. J. Plant Pathol. 109:705-713.

19. Munkvold, G. P., and Desjardins, A. E. 1997. Fumonisins in maize: can we reduce their occurrence? Plant Dis. 81:556-565.

20. Munkvold, G. P., McGee, D. C., and Carlton, W. M. 1997. Importance of different pathways for maize kernel infection by Fusarium moniliforme. Phytopathology 87:209-217.

21. Ncube E., Flett B. C., Waalwijk C., and Viljoen A. 2011. Fusarium spp. and levels of fumonisins in maize produced by subsistence farmers in South Africa. S. Afr. J. Sci. 107:1-7.

22. Pérez-Brito, D., Jeffers, D., Gonzalez-de-Leon, D., Khairallah, M., CortesCruz, M., Velazquez-Cardelas, G., Azpiroz-Rivero, S., and Srinivasan, G. 2001. QTL mapping of Fusarium moniliforme ear rot resistance in highland maize, Mexico. Agrociencia 35:181-196.

23. Presello, D. A., Iglesias, J., Botta, G., Reid, L. M., Lori, G. A., and Eyherabide, G. H. 2006. Stability of maize resistance to the ear rots caused by Fusarium graminearum and $F$. verticillioides in Argentinian and Canadian environments. Euphytica 147:403-407.

24. Rheeder, J. P., Marasas, W. F. O., Van Wyk, P. S., Du Toit, W., Pretorius, A. J., and Van Schalkwyk, D. J. 1990. Incidence of Fusarium and Diplodia species and other fungi in naturally infected grain of South African maize 
cultivars. Phytophylactica 22:97-102.

25. Rheeder, J. P., Marasas, W. F. O., Van Wyk, P. S., and Van Schalkwyk, D. J. 1990. Reaction of South African maize cultivars to ear inoculation with Fusarium moniliforme, F. graminearum and Diplodia maydis. Phytophylactica 22:213-218.

26. Rheeder, J. P., Marasas, W. F. O., and Vismer, H. F. 2002. Production of fumonisin analogs by Fusarium species. Appl. Environ. Microbiol. 68:2101-2105

27. Ritchie, S. W., Hanway, J. J., and Benson, G. O. 1993. How a corn plant develops. Iowa State Univ. Spec. Rep. No. 48.

28. Robertson-Hoyt, L. A., Kleinschmidt, C. E., White, D. G., Payne, G. A., Maragos, C. M., and Holland, J. B. 2006. Heritabilities and correlations of Fusarium ear rot resistance and fumonisin contamination resistance in two maize populations. Crop Sci. 46:353-361.

29. Schjøth, J. E., Tronsmo, A. M., and Sundheim, L. 2008. Resistance to Fusarium verticillioides in 20 Zambian maize hybrids. J. Phytopathol. 156:470-479.

30. Shelby, R. A., White, D. G., and Bauske, E. M. 1994. Differential fumonisin production in maize hybrids. Plant Dis. 78:582-584.

31. Shephard, G. S. 2008. Impact of mycotoxins on human health in developing countries. Food Addit. Contam. 25:146-151.

32. Shephard, G. S., Sydenham, E. W., Thiel, P. G., and Gelderblom, W. C. A. 1990. Quantitative determination of fumonisins $B_{1}$ and $B_{2}$ by high performance liquid chromatography with fluorescence detection. J. Liq. Chromatogr. 13:2077-2087.

33. Steiner, A. A. 1984. The universal nutrient solution. Pages 633-649 in: Proc 6th Int. Congr. Soilless Culture, Wageningen, The Netherlands.

34. Stockmann-Juvala, H., and Savolainen, K. 2008. A review of the toxic effects and mechanisms of action of fumonisin $B_{1}$. Hum. Exp. Toxicol. 27:799-809.

35. Van Egmond, H. P., Schothorst, R. C., and Jonker, M. A. 2007. Regulations relating to mycotoxins in food. Anal. Bioanal. Chem. 389:147-157.

36. Wagacha, J. M., and Muthomi, J. W. 2008. Mycotoxin problem in Africa: current status, implications to food safety and health and possible management strategies. Int. J. Food Microbiol. 124:1-12. 